\title{
Seguro-desemprego brasileiro: recuperando o debate sociopolítico sobre a sua criação
}

\author{
Moacyr Salles Ramos ${ }^{1}$
}

\begin{abstract}
Resumo
O artigo analisa o processo de criação do Seguro-desemprego brasileiro, com foco nos aspectos sociopolíticos que perpassaram esse período histórico. A partir de fontes secundárias, explicita características do mercado de trabalho e da luta dos trabalhadores no país, bem como a interferência dessas lutas na construção do Seguro- desemprego, a partir do processo de redemocratização nos anos 1980. Foi possível constatar que o Seguro-desemprego brasileiro é um programa fruto da solidariedade e da luta da classe trabalhadora, tendo sido criado tardiamente em nosso país, devido à nossa formação social, à culpabilização do trabalhador pelo desemprego e à forte repressão ao movimento sindical.
\end{abstract}

\section{Palavras chave}

Seguro-desemprego; mercado de trabalho; sindicatos.

Brazilian unemployment insurance: recovering the socio-political debate about its creation

\section{Resume}

the article analyzes the creation process of the Brazilian unemployment insurance, focusing on the socio-political aspects that crossed the historical period. From secondary sources, it explains characteristics of the labor market and the struggle of workers in the country, as well as the interference of these struggles, in the construction of unemployment insurance, from the process of redemocratization in the 1980s. It was possible to verify that insurance - Brazilian unemployment is a program resulting from solidarity and the struggle of the working class, having been created late in our country, due to social formation, the blaming of the worker for unemployment and the strong repression of the union movement.

\section{Keywords}

Unemployment insurance; labor market; unions

Artigo recebido em junho 2020

Artigo aprovado em agosto de 2020 


\section{Introdução}

O Seguro-desemprego brasileiro tem sido objeto de inúmeros debates desde a sua criação no ano de 1986. Nesse mesmo ano, foi publicada a tese de doutorado do professor José Paulo Zeetano Chahad, intitulada "Seguro-desemprego: lições das histórias, aspectos teóricos e perspectivas para o Brasil" (CHAHAD, 1986). O referido trabalho tem sua importância por apresentar a experiência internacional e também a nacional no que diz respeito à criação do Seguro-desemprego. Porém, por ter sido publicado no ano de criação do Seguro-desemprego, o trabalho em questão não pôde acompanhar os desdobramentos ocorridos a partir da criação desse programa no Brasil.

Posteriormente, outros trabalhos foram desenvolvidos, tais como o de Balera (1993); Luduvice (1999), já num contexto diferente daquele em que Chahad produziu a sua tese, isso pois, apesar de ter sido criado em 1986, o Seguro-desemprego foi inserido na Constituição Federal de 1988 e teve a sua primeira regulamentação apenas em 1990. Desde então, diversas dissertações e teses vêm sendo produzidas, discutindo problemas como o aumento de gastos, sua operacionalização, a integração do Seguro-desemprego com políticas de qualificação profissional e de intermediação da força de trabalho, dentre outras pautas.

No entanto, apesar das muitas contribuições de diversos pesquisadores, a literatura sobre o Seguro-desemprego brasileiro é incipiente no que diz respeito aos aspectos sociopolíticos que estiveram presentes na gênese desse seguro em nosso país, de modo que, ao ser analisado teoricamente, o Seguro-desemprego acaba sendo compreendido à parte de sua historicidade, bem como das especifıcidades da implementação do mesmo no Brasil, movimento que não acompanhou a tendência internacional.

A necessidade de revisitar a raiz do Seguro-desemprego na sociedade brasileira, explicitando suas contradições e as lutas sociais nele envolvidas, é também uma forma de ampliar a compreensão acerca de seu modus operandi nos dias de hoje, para além de análises con- 
tábeis. Isso, pois o Seguro-desemprego conserva até os dias atuais aspectos relativos ao pensamento social que o fez nascer tardiamente no Brasil e, nascendo, fez dele um programa restrito e limitado no amparo ao desempregado.

Pensemos no momento presente, no qual passamos por uma grave crise sanitária, devido ao coronavírus. Vivemos num cenário de fechamento generalizado de postos de trabalho, chegando ao final de maio com mais de 12 milhões de desempregados, considerando que esse número não abarca os que por conta da pandemia não estão procurando emprego ou não estão disponíveis para trabalhar (INSTITUTO BRASILEIRO DE GEOGRAFIA E ESTATÍSTICA, 2020).

O quadro caótico questiona as ações neoliberais até aqui implementadas por diversos governos tanto nas áreas da saúde e assistência como na área da previdência social, na qual se insere o Seguro-desemprego. Esse programa, apesar de hoje ter acesso restrito, limitado e condicionado, quando criado no Brasil, nos ares do processo de redemocratização, chegou a ser pleiteado por alguns setores da sociedade como um programa universal de apoio ao desempregado, com temporalidade extensa e sem condicionalidades. Qual foi o percurso dessa disputa de concepção? Quais atores e em qual cenário político se deu essa luta em torno da formação do Seguro-desemprego? Por que fomos um dos últimos países do mundo a criar um programa efetivo de amparo ao trabalhador demitido? Que especificidades temos na constituição desse programa?

Considerando esses questionamentos, o presente texto tem como objetivo principal discutir o movimento histórico e as tensões políticas que marcaram a criação do Seguro-desemprego Brasil, buscando contribuir com a construção de um debate teórico ainda necessário diante dos ataques do capital a essa política de amparo aos trabalhadores e também frente ao esvaziamento teórico sobre o assunto.

Nessa direção, esse artigo está dividido em duas partes. Após essa introdução, o leitor será convidado a refletir sobre alguns aspectos 
que influenciaram diretamente na construção do Seguro-desemprego brasileiro, que são: as singularidades do nosso mercado de trabalho e a forma como se deram as lutas dos trabalhadores pela conquista de direitos. Em seguida, passaremos a discutir mais especificamente as lutas e tensões que estiveram presentes (algumas ainda estão) na criação e na concepção Seguro-desemprego brasileiro.

\section{As singularidades do mercado de trabalho e das lutas dos trabalhadores no Brasil}

Ao longo do século XX, o Seguro-desemprego foi incorporado pelas economias capitalistas como um dos instrumentos de organização do mercado de trabalho e também como ferramenta de mediação dos conflitos entre capital e trabalho. Porém, tal incorporação se deu como resposta a luta da classe trabalhadora contra o pauperismo inicial durante o processo de industrialização. Assim, até a década de 1950, países como França, Dinamarca, Inglaterra, Finlândia, Alemanha, Itália, Áustria, Estados Unidos, dentre outros, já haviam criado seus seguros de amparo ao trabalhador desempregado.

No caso brasileiro, a formação social e a divisão social do trabalho tiveram desdobramentos relevantes nos processos de luta dos trabalhadores e na forma como as pautas reivindicatórias foram sendo incorporadas pelo Estado a partir do início da industrialização nacional. Tais elementos podem explicar o motivo de sermos um dos últimos países do mundo capitalista a criar o Seguro-desemprego, bem como o porquê de termos um dos programas mais restritos no que diz respeito as regras de habilitação, valores pagos e tempo de pagamento das parcelas.

Em nosso país, a passagem do Império para a República não garantiu todos os elementos necessários para uma revolução burguesa. Após a crise das oligarquias esse movimento de consolidação burguesa se deu em torno de interesses unicamente comerciais, dando forma ao Estado brasileiro, contudo não assumindo um papel pro- 
pulsor da modernidade, de modo universal. O escopo das lideranças nacionais era unicamente ganhar vantagem com as várias formas políticas, sociais e econômicas vigentes, de modo que o binômio avanço econômico e atraso político fez com que fosse protelada a abrangência universal de mudanças sociais inerentes ao mercado de trabalho livre (FERNANDES, 2006).

Com a crise de 1929 o mundo capitalista foi confrontado com o desenho preciso do desemprego como campo de intervenção estatal e, no Brasil, essa crise resultou em uma tomada de consciência, inclusive burguesa, das problemáticas relativas a uma economia voltada para o mercado externo, carecendo de reorganização das forças produtivas, especialmente na relação capital-trabalho (IANNI, 2009).

Desse modo, com transformações vindas “do alto”, é que Getúlio Vargas (1882-1954), apesar de ter perdido as eleições, conseguiu o apoio do Exército e de grupos políticos que viabilizaram um golpe que o colocou no poder em 1930, estabelecendo o governo provisório (1930-1934), a denominada revolução de 1930, como uma "revolução" sem a força dos trabalhadores.

Essa "revolução" demarcou o desenvolvimento de um tipo específico de Estado burguês, com alianças entre setores econômicos e políticos, instituindo novos valores sociais e buscando romper com o Estado Oligárquico. Há, a partir de então, o acionamento de um poder público, o planejamento do mercado de trabalho, a organização das forças produtivas e uma expressão clara e potente dessa transição: a evolução da legislação trabalhista (IANNI, 2009).

Convém lembrar que no campo interno havia lutas dos trabalhadores nesse início de século, inclusive foram elas que levantaram questões referentes à vida laboral que careciam de atenção. A lei de seguro de acidentes de trabalho de 1919 pode ser citada como fruto desses movimentos. Porém, por termos sido uma sociedade escravocrata até o final do século XIX, termos, no período, predominância de atividade rural e, por nossa proporção de país continental, tais lutas tinham 
muita dificuldade de se generalizar e envolver um espectro maior de trabalhadores (SÜSSEKIND, 1986).

Logo, se até a década de 1930 os canais de mediação estavam obstruídos, a partir de então a questão social passa a ser tida como legítima, reconhecida pelo próprio Getúlio Vargas que, em seu discurso de campanha à presidência, se colocou como cumpridor das normativas da Organização Internacional do Trabalho (OIT), a fim de estruturar o mercado e a legislação de proteção social. Tal intento foi se materializando na medida em que o Brasil ratificou as convenções da referida organização, totalizando a adesão a 12 convenções entre os anos 1934 e 1938 e 38 convenções entre os anos 1952 e 1969 (SÜSSEKIND, 1986).

Com isso, foram criados aparelhos de Estado com função de coerção e mediação dos conflitos sociais. Destaque especial teve o Ministério do Trabalho Indústria e Comércio, criado em 1930, considerado o "ministério da revolução", sendo, na prática, o "ministério da passivização". Este passou a regulamentar o mercado de acordo com os pressupostos internacionais, com os quais o Brasil se alinhou e passou a ter suas instituições como solucionadoras dos conflitos entre patrões e empregados. A função do Ministério do Trabalho era "pacificar as relações entre os vendedores e os compradores de força de trabalho no mercado urbano (setor secundário e terciário)" (IANNI, 2009, p. 44; CERQUEIRA FILHO, 1982).

Tratava-se da tentativa de alinhar capital-trabalho por meio de ações como a instituição de um salário mínimo, jornada de oito horas, férias, igualdade salarial, descanso semanal remunerado, regulamentação do trabalho noturno, assistência médica, proibição de trabalho aos menores de 14 anos, carteira de trabalho, previdência social, somados ao impulso do processo de industrialização representaram importantes incorporações de reivindicações dos trabalhadores². Porém, se, por um lado, houve avanços, por outro houve centralização do poder na pessoa do presidente e muita repressão às manifestações populares, além de controle político-jurídico dos sindicatos e demais organizações de tra- 
balhadores, que eram consideradas como cooperadoras do Ministério do Trabalho33 (CERQUEIRA FILHO, 1982; IANNI, 2009).

Além do exposto, a organização da previdência social, por categorias, teve um forte impulso, sendo a fragmentação das ações e ausência de planejamento características muito presentes e também desarticuladoras das organizações dos trabalhadores. O cenário era agravado pela incapacidade da proteção social vinculada ao trabalho assalariado de absorver a força de trabalho existente, especialmente a partir da migração campo-cidade, a vinda de pessoas de várias regiões, especialmente do Nordeste e da centralização da região Sudeste como concentradora da indústria nacional.

Dedecca (2005) defende que a principal razão da não expansão do modelo de contrato de trabalho trazido pela CLT e da proteção social referente a este modelo está no impedimento da ação sindical de modo livre. O espaço de negociação coletiva, que teria condições de estender e até mesmo de criar novos direitos, foi burocratizado e aparelhado pelo Estado varguista. Dessa forma, o controle e a passivização sindical durante o período foi importante para o modo de acumulação em curso, mas obstaculizou as bases de direitos dos trabalhadores no mercado.

No caso do Seguro-desemprego, a solidariedade de classe e as organizações dos trabalhadores que agiam de modo autônomo, em países industrializados, foram responsáveis por olhar não apenas para a criação de empregos, mas também em amparar os trabalhadores demitidos. A maturação dessa ação humanitária no bojo da luta de classe resultou numa processual incorporação desse princípio, de modos diversos, pelos Estados.

Conforme nos lembra Luduvice (1999) "quem primeiro se preocupou com os desempregados foram os sindicatos", de modo que "foi por causa de muita luta dos sindicatos de trabalhadores [...] que os países europeus começaram a intervir em favor dos desempregados". Por fim, "toda a iniciativa a respeito do desemprego surgiu inicialmente das entidades sindicais" (LUDUVICE, 1999, p. 18; 19). 
Entendemos que a perseguição aos sindicatos de oposição, a incorporação dos adeptos na estrutura do Ministério do Trabalho, somadas a segmentação das ações de previdência social, por categorias, tenham abortado a construção de ações mais amplas de proteção ao trabalhador demitido, ação que historicamente tem primazia no seio do movimento sindical, ainda que, posteriormente, incorporada no leque mais amplo das políticas sociais capitalistas.

Resumidamente, nossa tradição autoritária limitou as organizações dos trabalhadores e também a própria constituição da proteção social, de modo que estamos ainda muito aquém dos países centrais. Além do mais, o Seguro-desemprego nos países industrializados não foi incorporado à política social sem que se fizesse o enfrentamento da ideia de que estar desempregado era uma responsabilização individual e que o trabalhador nessa condição era um vadio, sendo o Seguro-desemprego um estímulo ao ócio.

Acerca de tais compreensões ideológicas, no Brasil, a transição da sociedade escravocrata para o livre mercado ocorreu conservando o mandonismo e os padrões ideológicos do passado servil, inclusive no que diz respeito ao ócio de boa parte dos escravos libertos e seus descendentes que, sem condições de disputar com imigrantes europeus as vagas no incipiente mercado e sem terras, engrossavam as fileiras de força de trabalho excedente, sendo por vezes considerados vadios. Ampliavam o rol de sobrantes, trabalhadores que participavam de atos, greves, os demitidos por diminuição da produção etc.

A ideologia da vadiagem constitui-se também como um obstáculo ao devido tratamento do desemprego e, consequentemente, dos desempregados. O decreto-lei 3.688/41 (BRASIL, 1941) determinava a prisão pelo "crime" de vadiagem ou mendicância. Eram enquadrados nesse crime bicheiros, prostitutas, pessoas sem documentos e também os que descumpriam a seguinte norma: "Entregar-se alguém habitualmente à ociosidade, sendo válido para o trabalho, sem ter renda que lhe assegure meios bastantes de subsistência, ou prover 
à própria subsistência mediante ocupação ilícita" (BRASIL, 1941, ART. 59). Em suma, era uma ferramenta de punição pela pobreza e pelo desemprego, o que vai na contramão do estabelecimento de ações de proteção ao desempregado.

Esse enfrentamento ideológico também precisou ser tratado no cenário internacional, em países como Inglaterra, Alemanha, etc. No entanto, a despeito dessas ideologias, as organizações sindicais começaram a tratar de modo direto com os desempregados, criando caixas de assistência, com objetivo de amparar não apenas os doentes e idosos, mas também os trabalhadores demitidos. Isso só foi possível devido a força política dessas organizações.

Na realidade brasileira não parece ter havido o mesmo movimento, nem por parte dos governos, nem dos sindicatos, de modo que entre 1930 e 1980 o país se colocou diante do problema da criação de emprego, negligenciando ações de amparo ao desempregado. Nesse processo destacam-se os anos 1950 que demarcou um profundo processo de acumulação capitalista, com a aplicação do Plano de Metas, abertura para investimentos estrangeiros atrelados a investimentos públicos de infraestrutura (DEDECCA, 2005; MEDEIROS, 2012).

Dessa forma foi possível realizar a expansão do parque industrial, com reestruturação da produção, adequando ao padrão estabelecido no pós-segunda guerra, cujo modelo era o fordista/taylorista, aplicado especialmente na produção automotiva, cuja expressão de destaque foi o $A B C$ Paulista. O surgimento da classe operária se deu junto com uma inflexão na atuação do Estado, que se abriu para o mercado internacional, aproveitando-se da fraca resistência sindical diante das mudanças no processo produtivo. Esse quadro gerou um tipo de fordismo típico de um país de capitalismo dependente, que teve ainda marcas repressoras a partir da ditadura de 1964 (MEDEIROS, 2012).

Diferentemente do fordismo-keynesianismo vivido nos países centrais, o "modo brasileiro" não garantiu a construção dos canais de mediação dos conflitos de classe por meio dos direitos do trabalho 
e do pleno emprego. Ao contrário disso, durante a ditadura militar, eliminou-se um dos direitos mais valiosos para a classe trabalhadora: a estabilidade no emprego, garantida pela CLT. Ao passo em que desmontado esse importante instrumento protetivo do trabalho, impedia greves e manifestações contrárias ao governo, criando um ambiente favorável para a implementação do autoritarismo dentro e fora dos locais de trabalho.

Foi com o fim da estabilidade no emprego que teve início a organização de um sistema de amparo ao trabalhador demitido, ainda que precário e sem a participação dos trabalhadores. Em 1966 e 1967, respectivamente, foram criados o "auxílio desemprego" e o Fundo de Carantia por Tempo de Serviço (FGTS).

Essa mudança foi realizada tanto por manobras institucionais, como por uma forte campanha governamental, que buscava constranger os trabalhadores a não desejarem indenizações com o fim das relações de trabalho, colocando o FGTS como solução para todos os males atribuídos a estabilidade, tais como acomodação do trabalhador, dentre outros.

\section{Lutas e tensões na constituição do Seguro-desemprego brasileiro}

Apesar de serem o "auxílio-desemprego" e o FGTS formas de garantir ao patrão a liberdade para demitir, possibilitando maior flexibilização do mercado de trabalho, por outro lado também traziam uma compensação para os que, por manobras empresariais, eram demitidos antes de completados 10 anos de trabalho. Porém, parece claro que, se a estabilidade fosse importante para o governo, as ações seriam de controle, fiscalização e regulação do empresariado e não de mera compensação ao trabalhador.

Sobre o auxílio-desemprego desse período, Chahad (1986) entende que a canalização de recursos do Ministério do Trabalho e da folha de pagamentos dos trabalhadores para tal fim buscou amenizar os conflitos entre patrões e empregados, instituindo a negociação como regra para 
as questões referentes à demissão, podendo ser tomadas ações como redução da jornada de trabalho em casos de crise, com compromisso da empresa em recontratar os demitidos em casos de recuperação.

Antes de acabar com a estabilidade dos trabalhadores, o governo militar desenhou uma estrutura de acompanhamento do processo demissional. Em 1965, com o Decreto 4.923/65 (BRASIL, 1965), havia instituído, no âmbito do Ministério do Trabalho, o Cadastro de Admissões e Dispensas de Empregados, que era alimentado de informações pelas empresas. A mesma lei determinou que a assistência aos desempregados se daria via previdência social, por meio de um pagamento que não poderia exceder $80 \%$ do salário mínimo, nem o prazo de seis meses, ou seja, as bases do auxílio-desemprego de 1966.

No mais, a lei instituiu uma comissão de estudo do Seguro-desemprego, formada por três representantes de trabalhadores, empregadores e do governo. Esta teria como função criar o anteprojeto de lei do Seguro-desemprego. Não obstante, não há registros dos resultados desta comissão na literatura sobre o tema. Balera (1993) cita um relatório publicado pela Revista de Previdência Social, n. 45, em que está escrito que a comissão escolheu não buscar solução para certas questões, dentre as quais a criação do Seguro-desemprego.

Em 1966 foi criado o Fundo de Assistência ao Desempregado (FAD), que deveria custear o auxílio-desemprego para o trabalhador que tivesse 120 dias de trabalho com carteira assinada. No caso, o auxílio seria de 50\% do valor do salário mínimo e apenas por, no máximo, três meses. Na direção de restrição, veio o Decreto 58.155/66 (BRASIL, 1966) determinando que o auxílio seria pago para casos de fechamento total ou parcial da empresa e por demissão de mais de 50 funcionários, devido a modificações estruturais.

Traçando um paralelo dessas normativas com as Constituições Federais do período, temos a de 1967, que coloca o Seguro-desemprego na “letra da lei", igualando a sua raiz previdenciária com a proteção à maternidade, doença, velhice, invalidez e morte, no artigo 158, inciso XVI. 
Mas, destaca-se que ao colocar o Seguro-desemprego no rol previdenciário também o situa no modelo de financiamento empregador-trabaIhador-governo, o que não se verificava até o momento (BALERA, 1993).

Temos então uma mudança de paradigma, considerando que outrora todas as normativas vigentes tratavam da assistência ao desempregado e agora este item é posto como um tipo de seguro, embora não tenha sido posta em prática nenhuma ação que consubstanciasse um seguro social, vigorando ainda as bases assistenciais, o que caracterizou “um jogo protelatório" (BALERA, 1993, p. 43).

Ao que parece, esse atraso na constituição do Seguro-desemprego, além da ausência do protagonismo sindical, tem relação com um total descompasso entre os decretos e a Constituição, com grande confusão terminológica e descaracterização de ideias já estruturadas nos sistemas econômicos internacionais. Isso, pois, apesar de não existir no Brasil, o Seguro-desemprego já era uma instituição capitalista antiga e validada socialmente. No entanto o Brasil foi, ao longo da década de 1960, em momentos se afastando e em outros se aproximando da criação desse tipo de seguro. Não obstante, predominou o afastamento, principalmente, a partir do "milagre econômico".

O chamado "milagre econômico" se deu na virada dos anos 1960 para 1970, com a expansão do mercado de trabalho, crescimento industrial, geração de empregos, crescimento do PIB a 14\%, em 1973, e baixa inflação com expansão do consumo interno. Isso com endividamento público, intensificação da exploração da força de trabalho, aumento da concentração de renda nas mãos dos mais ricos e forte repressão social imposta pelo Ato Institucional n. 5 (Al-5), que vigorou entre 1968 e 1978. (POCHMANN, 2009; ANTUNES, 1999).

Todavia, esse crescimento econômico não foi capaz de incorporar as massas trabalhadoras ao trabalho assalariado, impossibilitando também a produção e o consumo de massa. Além disso, durante o governo militar houve arrocho salarial dos mais pobres, ao invés de aumentos. Assim, a movimentação da força de trabalho, especialmente 
pela transição campo-cidade, com concentração da força de trabalho nos grandes centros urbanos e rotatividade no mercado assalariado e o fim do "milagre econômico" contribuíram com a importância de criação do Seguro-desemprego nacional. Segundo Chahad (1986):

O crescimento da proporção dos assalariados no mercado de trabalho, se por um lado deve ser visto como algo inevitável quando o país se industrializa, e sob determinados aspectos, representa uma situação melhor para a classe trabalhadora, por outro vem a significar que um contingente crescente de trabaIhadores passa a ser vulnerável às flutuações da atividade econômica, ou seja, passam todos a serem desempregados potenciais. Nesse sentido o assalariamento e a urbanização acabam por revelar um novo fenômeno para a sociedade, o do desemprego urbano, formado por um contingente de trabalhadores sem ocupação, aptos ao trabalho e realizando efetivamente esforços para obter emprego, sem, contudo, ter êxito nessa missão (CHAHAD, 1986, p. 223).

O desemprego urbano passou a ser importante no cenário nacional, de modo que, nos anos 1980, devido à grande recessão que atingia o país, iniciou-se a pesquisa de emprego e desemprego na cidade de São Paulo, numa conjuntura de luta pela redemocratização, de esgotamento do modelo econômico de substituição de importações, de perda salarial e alta da inflação. No período, observou-se uma retomada no engajamento político do movimento sindical, em busca de soluções tanto para o desemprego como para a democracia. A oposição trabalhista se organiza com a criação do Partido dos Trabalhadores (PT) e das Centrais Sindicais. Segundo Dedecca (2005, p. 121):

A emergência do desemprego não foi observada de maneira homogênea no território nacional. Sua ocorrência ficou, em grande medida, restrita às zonas urbanas com maior densidade industrial, que possuíam inclusive um mercado de trabalho com maior presença da regulação social existente. É por esse motivo que a 
Grande São Paulo despontou também como o centro da crise social. Boa parte dos desempregados era originária de grandes empresas industriais, possuindo a situação de assalariamento como única trajetória realizada no mercado de trabalho. Para a grande maioria, a perda do emprego se traduziu, em um primeiro momento, na situação de desemprego aberto. Entretanto, a falta de um sistema de Seguro-desemprego induzia que, posteriormente, a situação de desocupação fosse associada a algum tipo de atividade irregular que pudesse viabilizar a própria sobrevivência ou financiar a procura de um novo posto de trabalho.

Destarte, foi durante o processo de redemocratização e de grande recessão econômica que o Seguro-desemprego entrou "na ordem do dia", por conta da pressão dos trabalhadores, como as greves dos metalúrgicos e de outras categorias na passagem para a década de 1980. Tal fato pode ser comprovado pelo aumento de Projetos de Lei para instituir o seguro, que de uma única proposta em 1975 saltou para nove em 1983 (CHAHAD, 1986).

Convém destacar que, apesar de pouco evidenciada na literatura nacional, a luta dos trabalhadores contribuiu para que o Seguro-desemprego não fosse mais uma vez deixado de lado, com destaque para as pautas da Central Única dos Trabalhadores (CUT) acerca do tema. Vejamos.

Em sua primeira resolução, na ocasião da $1^{a}$ Conferência Nacional da Classe Trabalhadora, em 1981, a CUT vinculava o Seguro-desemprego ao trabalho como um direito a ser garantido pelo Estado. Assim, não cogitava um seguro que findasse enquanto o desemprego involuntário existisse. Tal pauta não vem de modo isolado, mas vem junto com a luta pela estabilidade perdida durante a ditadura militar e com uma resistência a automação trazida pelo processo de reestruturação produtiva (CENTRAL ÚNICA DOS TRABALHADORES, 1981).

Em 1983, no $1^{\circ}$ Congresso Nacional da Classe Trabalhadora, a proposta de ampliação do tempo de seguro (agora chamado salário- 
-desemprego) se mantém, mas o rol de trabalhadores atendidos se expande, englobando também os trabalhadores rurais e até os sem vínculo empregatício (CENTRAL ÚNICA DOS TRABALHADORES, 1983).

No ano de 1984, no $1^{\circ}$ Congresso Nacional da CUT, a Central denuncia a letargia brasileira acerca do assunto diante do elevado número de desempregados e, finalmente, em 1986, ano em que foi criado o Seguro-desemprego, a CUT se posiciona em seu $2^{\circ}$ Congresso Nacional da CUT contra a rigidez impressa na Lei 2.284/86 (BRASIL, 1986), que exigia "condições absurdas", excluindo a maioria dos trabalhadores do direito de receber as parcelas do seguro, e reafirma a necessidade da generalização do seguro a todos os trabalhadores em situação de desemprego involuntário (CENTRAL ÚNICA DOS TRABALHADORES,1984; 1986).

Dessa forma, é possível dizer que até a instituição do Seguro-desemprego, em 1986, a CUT manteve um padrão de oposição direta ao modelo restrito e rígido das propostas governamentais de proteção ao desempregado trazidas como solução para a crise dos anos 1980. Dessa maneira, merece registro a posição da CUT no período de redemocratização, quando disputava com as concepções do empresariado acerca do Seguro-desemprego, confirmando que a proteção do desempregado era também uma disputa de classes, no âmbito do Estado, que se materializaria na legislação.

Ao ímpeto sindical se agregava o debate social realizado pela mídia sobre o desemprego, com "avalanche de textos de cunho jornalísticos evidenciando a importância e a necessidade do Seguro-desemprego para enfrentar o trauma pelo qual passava a sociedade" (CHAHAD, 1986, 251). Ambos os elementos fomentaram assim uma grande oportunidade política em torno da criação do Seguro-desemprego (LUDUVICE, 1999), juntamente com o Plano Cruzado 4.

Notemos, como já aludido, o Seguro-desemprego foi criado por meio do Decreto 2.284/86 (BRASIL, 1986), que instituiu essa indenização para demissões sem justa causa, assim como para casos de pa- 
ralisação total ou parcial da empresa. A respeito desse decreto, Balera (1993) entende se tratar ainda de uma extensão da assistência que vinha sendo mantida ao longo dos anos.

Contudo, apesar de entendermos as limitações de alcance, destacamos que criou-se uma perspectiva segurancial, devido as seguintes condições: contribuições do trabalhador à previdência social durante 36 meses, nos últimos quatro anos, somados aos seis meses de carteira assinada e o fato de ter sido dispensado, sem ter conseguido novo emprego, por mais de 30 dias.

Apesar da dureza das regras, ao nosso ver o comprometimento com a contribuição previdenciária é uma aproximação da formatação do seguro, isso, pois não se avalia o trabalhador apenas pelo critério da "necessidade". Exige-se dele contrapartidas específicas, ainda que absurdas, ao passo em que compromete o Estado a executar o pagamento. Por equivaler a um amplo processo de exclusão dos demitidos, essa norma também foi duramente criticada pela CUT.

Sobre a fonte de pagamento, o decreto indica o FAD, mas aponta que a partir de 1987 os pagamentos deveriam ser feitos de outra forma, o que, por sua vez, seria resultado de contribuições do Estado, dos trabalhadores e dos empregadores.

A despeito do austero regulamento do Seguro-desemprego, que inviabilizava o acesso de muitos trabalhadores, ainda em 1986 foi promulgado o Decreto 92.608/86 (BRASIL, 1986a), que o tornou ainda mais inclemente. $\mathrm{O}$ decreto trouxe o esteio conservador da assistência, com base na necessidade, afastando, desse modo, a concepção de seguro.

$\mathrm{Na}$ prática o referido decreto ampliou para 60 dias o tempo de desemprego para solicitar o seguro, manteve as longas contribuições para regime de previdência e acrescentou como regra não possuir renda de qualquer natureza que desse para manter a família, além de não estar em gozo de nenhum benefício previdenciário. Se fez, dessa forma, uma mistura entre princípios assistencialistas e seguranciais. Quanto ao pagamento, esse seria variável de acordo com os salá- 
rios anteriores, mas não inferior a 70\% do salário mínimo. Ou seja, a reposição de renda sequer tomava como base o salário mínimo, estabelecendo um subsalário.

Essas mudanças combinavam muitos pré-requisitos para solicitar o seguro, longa espera para passar a receber, baixa reposição salarial com curta duração das parcelas, sendo, por essas causas, um tipo de seguro muito criticado e pouco usufruído pelos trabaIhadores. Basta considerarmos que a baixa abrangência desse seguro no ano de sua criação, que teve apenas 204.324 mil requerentes e 150.751 segurados, correspondente a uma taxa de habilitação de pouco mais de 73\% (BRASIL, 2019).

A criação do Seguro-desemprego, na realidade, nunca se tratou de uma questão apenas contábil, mas principalmente ideológica. As resistências, até mesmo pós 1986, se baseavam em argumentos superficiais, moralistas e desconfiados. Os principais eram: o seguro incentiva a preguiça do trabalhador; os trabalhadores vão fazer uso de fraudes para gozar das parcelas; os seguros não deram certo nos países desenvolvidos e estes estão recuando; ao invés de pagar seguro é melhor investir na geração de emprego; o seguro não seria positivo no Brasil, porque o país tem muita informalidade; não existem recursos (CHAHAD, 1986).

Talvez, por tamanha resistência, o Seguro-desemprego aprovado na Assembleia Nacional Constituinte (1987) tenha sofrido um rebaixamento, com relação ao projeto original, que era mais amplo e orgânico em seus laços com a seguridade social. O anteprojeto elaborado pelo professor Afonso Arinos de Melo Franco, juntamente com outros especialistas em seguridade social, como Evaristo de Moraes Filho e Moacyr Veloso Cardoso, a pedido do presidente José Sarney, trazia para a Constituinte princípios de direito ao trabalho e pleno emprego. Ainda colocavam no campo da seguridade social a cobertura do Seguro-desemprego, extensivo para todos os trabalhadores, sendo assim enquadrado como benefício universal da seguridade social. Porém tal anteprojeto não foi encaminhado ao congresso por José Sarney (BALERA, 1993). 
Tendo iniciado as atividades da Constituinte, foram divididos os grupos de trabalho por tema. Em junho de 1987, foi submetida à comissão de sistematização constitucional a parte que tratava da ordem social. Esta, por sua vez, assegurava a todos os trabalhadores urbanos e rurais, até mesmo servidores públicos de todas as esferas, o Seguro- desemprego em caso de demissão involuntária. A proteção deveria ser compatível com o último salário e ter a duração nivelada pelo tempo de desemprego no país (BALERA, 1993).

Para dar conta de um Seguro-desemprego amplo, seria criado o Fundo de Garantia do Seguro-desemprego, que seria gerido de modo tripartite. Esse fundo seria integrante do orçamento geral da Seguridade Social, poderia ser aplicado em programas de interesse social e seria acrescido de um adicional para empresas cuja dispensa fosse superior aos índices médios de rotatividade. Nesse caminho, o FGTS seria extinto e o Programa de Integração Social (PIS) e o Programa de Formação do Patrimônio do Servidor Público (PASEP) constituiriam a parte do empregador para o fundo. Contudo o anteprojeto foi totalmente desfigurado, por meio de diversas emendas propostas, especialmente pelo "centrão" , e por um conjunto de negociações que eram frutos de convicções políticas sobre o programa (BALERA, 1993).

À época da apresentação do projeto de regulamentação do Seguro-desemprego, o deputado federal Jorge Uequede (PMDB) fez uma justificativa que parece sintetizar adequadamente os impasses que permeavam os debates sobre Seguro-desemprego até a promulgação da Constituição de 1988. Apesar de extenso, por seu potencial elucidativo, o transcrevemos abaixo. Após explicar o Seguro-desemprego em diversos países do mundo, questiona:

E no Brasil, que registros de instrumentos legais podem revelar uma possível trajetória que consubstancie intenção de se instituir o Seguro-desemprego? Na verdade, a proteção ao trabalhador que perde o emprego, não obstante objeto de algumas referências em nossa legislação, inclusive em textos constitucionais, 
esteve sempre bloqueada face às omissões governamentais e em documentos regulamentadores da matéria. Não têm sido poucos os artifícios protelatórios à execução de um plano de Seguro-desemprego em nosso país, alguns baseados em falsos argumentos oficiais de que não cabia a instituição do benefício, porque "a economia brasileira atravessa fase de pleno emprego", conforme se proclamou insistentemente na primeira metade dos anos setenta, um corolário da visionária tese do milagre brasileiro. Demonstrando absoluta convergência de interesses, governantes e empresários brasileiros têm utilizado, nas últimas décadas, a mesma argumentação para inviabilizar essa importante conquista à classe trabalhadora: nos períodos de maior crescimento econômico, aproveitam-se da referida assertiva, segundo a qual o desemprego tenderia a registrar níveis pouco significativos, situação que, teoricamente, dispensaria a existência do respectivo seguro. Nos tempos de recessão e crise, a justificativa passa a ser a falta de recursos para custear o programa do Seguro-desemprego, bem assim a escolha de outras áreas de reconhecida carência para a suposta aplicação de verbas orçamentárias. Graças a tal malabarismo retórico, facilitado pelas condições político-institucionais do longo período ditatorial que vitimou a Nação em recente passado, a implantação do Seguro-desemprego foi sendo sistematicamente postergada, como também suas possiveis fontes de sustentação tiveram os recursos desviados para financiar projetos contrários aos interesses dos trabalhadores (UEQUED, 1988, p. 7).

Diferentemente das demais Constituições, a de 1988 tem também o seu mérito na defınição das fontes de financiamento, sendo as principais o PIS/PASEP, conforme descrito no artigo 239 da referida carta magna. Além disso, ela cria um mecanismo de proteção contra a despedida arbitrária e a rotatividade, pois permite a cobrança de um adicional do empregador para casos em que a rotatividade supere o índice médio. Essa seria uma forma de envolver os patrões na problemática do desemprego, mas até os dias de hoje, esse dispositivo não foi regulamentado. 
Outra novidade foi o termo "Programa Seguro-desemprego", acoIhido na regulamentação dessa ação realizada nos anos 1990, por meio da Lei 7. 998/90 (BRASIL, 1990), que não se restringiu apenas ao pagamento de parcelas pecuniárias, mas também a ações integradas de qualificação e intermediação da força de trabalho. Luduvice (1999) explica que não se tratou de acaso inserir o termo "programa". O que de fato ocorreu foi a criação de uma política em que o tradicional Seguro-desemprego, entendido como pagamento, se juntasse às políticas de criação de emprego e de organização e desenvolvimento do mercado de trabalho nacional.

\section{Considerações Finais}

O debate sobre a constituição do Seguro-desemprego brasileiro, com destaque para os impasses entre os interesses dos trabalhadores e os do capital, é de suma importância para que esse programa não seja entendido apartado das contradições inerentes às lutas sociais e políticas no interior do Estado capitalista.

Apesar de ser objetivo de diversas pesquisas e despertar grande interesse social, o Seguro-desemprego tem sido analisado predominantemente sob a ótica contábil, em especial quando a intenção é reduzir os "gastos" com o programa. Além disso, no que tange a sua história, esse programa tende a ser associado ao Estado de Bem estar Social, vivido por alguns países do mundo capitalista, fato que o desloca de sua origem de classe, ou seja, do surgimento de ações de amparo aos desempregados no interior das organizações da classe trabalhadora, ou seja, nos sindicatos.

Nesse sentido, as reflexões apresentadas nos permitem resgatar o elo histórico entre a proteção aos desempregados e as organizações sindicais. Além de compreendermos que a constituição do Seguro-desemprego no Brasil conflitou com as concepções individualistas e culpabilizadoras sobre o desemprego, com forte juízo moral sobre o desempregado. 
A criação do Seguro-desemprego foi adiada e substituída por medidas paliativas até o final da ditadura militar, fazendo com que essa demanda se expressasse nas pautas do movimento sindical pós-ditadura. Assim, foram nos ares da redemocratização, com maior oposição sindical e debate social de modo geral, que esse direito foi finalmente conquistado, apesar de conservar limitações estruturais que impediam e ainda impedem a sua generalização.

\section{Referências}

ANTUNES, Ricardo. Os sentidos do trabalho: ensaio sobre a afırmação e a negação do trabalho. São Paulo: Boitempo, 1999.

BALERA. W. O Seguro-desemprego no direito brasileiro. São Paulo: Editora LTr, 1993. BRASIL. MINISTÉRIO DA ECONOMIA. Histórico do Seguro-desemprego Trabalhador Formal. Brasília, DF. 2019. Disponivel em: http://trabalho.gov.br/ dados-abertos/estatistica-Seguro-desemprego. Acesso em: 02 ago. 2019.

BRASIL. Decreto-Lei 2.284, de 10 de março de 1986. Mantém a nova unidade do sistema monetário brasileiro, o Seguro-desemprego, amplia e consolida as medidas de combate à inflação. Brasília, DF, 1986. Disponível em: https://www2.camara.leg.br/legin/fed/declei/1980-1987/decreto-lei-2284-10-marco-1986-367002-norma-pe.html. Acesso em: 15 jun. 2020.

BRASIL. Decreto-Lei 3.688 de 3 de outubro de 1941. Lei das Contravenções Penais. Disponivel em: http://www.planalto.gov.br/ccivil_03/decreto-lei/ del3688.htm. Acesso em: 13 mar. 2020.

BRASIL. Lei 4.923, de 23 de dezembro de 1965. Brasília, DF, 1965. Institui o Cadastro Permanente das Admissões e Dispensas de Empregados, Estabelece Medidas Contra o Desemprego e de Assistência aos Desempregados, e dá outras Providências. Disponível em: https://legislacao.presidencia.gov. $\mathrm{br} /$ atos $/$ ?tipo $=$ LEI\&numero $=4923 \&$ ano $=1965 \&$ ato $=5$ ceETWE5UeZRVTd 88 . Acesso em: 20 set. 2019.

BRASIL. Decreto 58.155, de 05 de abril de 1966. Brasilia, DF, 1966. Constitui o "Fundo de Assistência ao Desempregado", regulamenta sua aplicação pelo Ministério do Trabalho e Previdência Social, e dá outras providências. Disponivel em: https://legislacao.presidencia.gov.br/atos/?tipo=DEC\&numero=58155\&ano=1966\&ato=fbdcXUq5UMZRVT42f. Acesso em: O2 set. 2019. 
BRASIL. Projeto de Lei No 991, de 1988. Disciplina a concessão do seguro- desemprego. Brasília, DF, 1988 Disponível em: https://www.camara. leg.br/proposicoesWeb/fichadetramitacao?idProposicao=185613. Acesso em: 10 jun. 2020.

BRASIL. Lei 7.998, de 11 de janeiro de 1990. Regula o Programa do Seguro-Desemprego, o Abono Salarial, institui o Fundo de Amparo ao Trabalhador (FAT), e dá outras providências. Brasília, DF, 1990. Disponível em: http:// www.planalto.gov.br/ccivil_03/leis/L7998.htm. Acesso em: 19 ago. 2018.

CENTRAL ÚNICA DOS TRABALHADORES - CUT. Resolução da Conferência Nacional da Classe Trabalhadora, 1981. Disponível em: http://cedoc.cut.org. br/cedoc/resolucoes-de-congressos/111. Acesso em: 15 jun. 2020.

CENTRAL ÚNICA DOS TRABALHADORES. $1^{\circ}$ Congresso Nacional da Classe Trabalhadora, 1983. Disponivel em: http://cedoc.cut.org.br/cedoc/resolucoes-de-congressos/113. Acesso em: 15 jun. 2020.

CENTRAL ÚNICA DOS TRABALHADORES - CUT. $1^{\circ}$ Congresso Nacional $d a$ CUT, 1984. Disponivel em: http://cedoc.cut.org.br/cedoc/resolucoes-de-congressos/114. Acesso em: 15 jun. 2020.

CENTRAL ÚNICA DOS TRABALHADORES - CUT. $2^{\circ}$ Congresso Nacional $d a$ CUT, 1986. Disponivel em: http://cedoc.cut.org.br/cedoc/resolucoes-de-congressos/115. Acesso em: 15 jul. 2020.

CHAHAD, Jose Paulo Zeetano. Seguro-desemprego: lições da história, aspectos teóricos e perspectivas para o Brasil. Ensaios Econômicos, São Paulo: IPE-USP, 1986.

CERQUEIRA FILHO. Gisalio. A questão social no Brasil: crítica do discurso político. Rio de Janeiro: Civilização Brasileira, 1982.

DEDECA, Claudio. S. Notas sobre a Evolução do Mercado de Trabalho no Brasil. Revista de Economia Política, vol. 25, n 1 (97), pp. 113-130, janeiro-março/2005.

FERNANDES, Florestan. A revolução burguesa no Brasil. 5. ed. São Paulo: Globo, 2006.

INSTITUTO BRASILEIRO DE GEOGRAFIA E ESTATÍSTICA. Pesquisa Nacional por Amostra de Domicílio (PNAD) 2020. Disponível em: https://www.ibge. gov.br/busca.html?searchword=desemprego\&searchphrase=all. Acesso: 29 jun. 2020. 
IANNI, Octavio. Estado e planejamento econômico no Brasil. Rio de Janeiro: Editora UFRJ, 2009.

LUDUVICE, Ricardo Verta. Seguro-desemprego. São Paulo: Editora Atlas S.A., 1999.

MEDEIROS, M. S. F. Especificidades e Mudanças nos Modelos Produtivos no Brasil. Rio de Janeiro: [2012], mimeo.

POCHMANN, M. O trabalho na crise econômica no Brasil: primeiros sinais. Estudos avançados. vol. 23 no.66, 2009.

SÜSSEKIND, Arnaldo. O Brasil e a Organização Internacional do Trabalho. Revista do Tribunal Superior do Trabalho, São Paulo, v. 55, p. 105-116, 1986.

UEQUED, J. Projeto de Lei No 9.991, de 1988. Disciplina a concessão do seguro- desemprego. Brasília, DF, 1988 Disponível em: https://www.camara.leg. br/proposicoesWeb/prop_mostrarintegra;jsessionid=7B044235C348B627A6F44726CBD6D667.node1?codteor=1154517\&filename=Avulso+-PL+991/1988. Acesso em: 10 mai. 2020.

\section{Notas}

1 Doutor em Serviço Social pela Pontifícia Universidade Católica do Rio de Janeiro (PUC- Rio). Universidade Federal Fluminense (UFF). Brasil. ORCID: https://orcid. org/0000-0002-6192-777X.E-mail: mramos@id.uff.br.

2 Todas essas mudanças integraram a Consolidação das Leis Trabalhistas (CLT), em 1943.

3 Nesse arranjo foi criado o imposto sindical, regulamentado pela CLT, determinando que a remuneração de um dia de trabalho de todo assalariado fosse destinada ao sindicato, mas apenas aos reconhecidos pelo Ministério do Trabalho.

4 O Plano Cruzado foi um conjunto de medidas econômicas, lançado pelo governo brasileiro em 28 de fevereiro de 1986, com base no decreto-lei n².283, de 27 de fevereiro de 1986, sendo José Sarney o presidente da República e Dilson Funaro o ministro da Fazenda.

5 Historicamente, o "centrão" aglutina partidos políticos que não possuem afinidades ideológicas explícitas nem com a "direita", nem com a "esquerda", estando no transito entre ambas as perspectivas, de acordo com os seus interesses de negociação. 


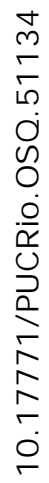

용 